\title{
Evaluation of endsocopic brush and biopsy touch smear cytology and biopsy histology in the diagnosis of carcinoma of the lower oesophagus and cardia*
}

\author{
JENNIFER A YOUNG, HELENA E HUGHES, AND FD LEE \\ From the Departments of Cytology and Pathology, The Royal Infirmary, Glasgow, UK
}

SUMMARY A four-year prospective study of endoscopic cytology and histology was carried out on 64 patients suspected of having a malignant lesion at the junction of the lower oesophagus and cardia. The final diagnosis was malignant in 18 and benign in 46 cases. Biopsy touch smear cytology was the most accurate technique with a sensitivity of $100 \%$ compared with $82 \%$ for brush cytology and $89 \%$ for biopsy histology. There was one false positive endoscopic histology report, but no false positive cytology result. Biopsy touch smear cytology is at present a method little used in the digestive tract. This study demonstrates its value in the diagnostically difficult area of the gastrooesophageal junction.

Endoscopic brush cytology and biopsy histology are now well established techniques for the diagnosis of squamous cell carcinoma of the oesophagus ${ }^{1-3}$ and adenocarcinoma of the stomach. ${ }^{1-5}$ The lower oesophagus and cardia, however, remain difficult areas for endoscopic diagnosis. Stenosis may impede the collection of adequate specimens for histology or cytology, while the submucosal nature of some infiltrative tumours may preclude satisfactory sampling by superficial biopsy or brushing techniques. In addition, the variety of epithelial tumours which arise in this junctional zone is greater than in the main organs above and below, and the cellular material is frequently poorly differentiated. This may lead to difficulties in cytological tumour typing. Some authors have reported the diagnostic accuracy of brush cytology to be $30-40 \%$ higher than that of biopsy histology in the lower oesophagus ${ }^{3} 6$ and cardia, ${ }^{7}$ while others have found histology to be superior by as much as $17 \%{ }^{8}$ In order to evaluate the comparative usefulness of cytology and histology in the diagnosis of carcinoma of the gastro-oesophageal junction, a four-year prospective study has been undertaken. The trial was designed to compare the accuracy of routine histological examination of biopsies with cytological examination not only of brush specimens but also of biopsy touch smears.

\footnotetext{
*Based on a communication presented to the 9th European Congress of Cytology, Brighton, UK, 26-28 September 1979.
}

Received for publication 14 February 1980

\section{Methods}

During the four-year period 1974 to 1977 , endoscopic cytology and histology specimens were examined from the upper digestive tract of 446 patients. Sixty-four of these patients were suspected clinically or radiologically of having a malignant lesion of the lower oesophagus or cardia, and it is these cases which form the basis of the present report.

Brush specimens were collected from 56 of the cases and biopsies for histology and touch smears from all 64 patients. The number of biopsies was left to the judgement of individual clinicians and varied between one and seven per patient. The methods of collection, preparation, staining, and reporting were similar to those previously described for use with gastric specimens. ${ }^{59}$ From four to six direct smears and a saline suspension for processing on to Millipore filters werc made from each brush, and six to eight touch smears for cytology were made from each biopsy before fixation for histology. Great care is needed in preparation of the touch smears. The biopsy is transferred from the forceps to a slide with a fine (21G) needle, and the smear is then made by very gently rotating the tissue with the needle. This procedure is repeated on the required number of slides, and the biopsy is then placed in formol saline. Examination of matched pairs of biopsies with and without preceding touch smears had shown that the quality of the biopsies for histology was not impaired by the touch smear technique. The cytology was reported by two of the 
authors (JAY and HEH) throughout the study. The policy was to make a definitive diagnosis in all cases, and 'suspicious' cytology reports were not issued. The histology was reported by the duty pathologist under the supervision of FDL. Two 'suspicious' histology reports were issued during the four-year period.

\section{Results}

The material obtained was adequate for cytology in 62 cases $(97 \%)$ and was suitable for histological assessment in 60 cases $(94 \%)$. From the two techniques, however, sufficient material for diagnostic purposes was obtained in all 64 patients. To enable a valid comparison to be made of the clinical usefulness of cytology and histology the two cases with unsatisfactory cytology and the four cases with unsatisfactory histology have been considered as 'providing no evidence of malignancy' and placed with the negative results for analysis. The two 'suspicious' histology reports have been grouped with the positive results, and malignancy was subsequently confirmed in both cases.

The overall results for cytology and histology are shown in Table 1. These were analysed for both sensitivity and specificity. ${ }^{10}$ The definition of the former is 'the ability of the test to give a positive finding when the individual screened has the disease under investigation', and the definition of the latter is 'the ability of the test to give a negative finding when the individual does not have the disease under investigation'. The value of a test in establishing either the presence or the absence of a disease can thus be measured, as there is a check on both false negative and false positive errors.

Table 1 Results of cytology (brush and touch smear) and biopsy histology in 64 cases

\begin{tabular}{|c|c|c|c|c|c|}
\hline \multirow[t]{2}{*}{ Test result } & \multirow[t]{2}{*}{ No. } & \multicolumn{2}{|c|}{ Final diagnosis } & \multirow[t]{2}{*}{ Sensitivity* } & \multirow[t]{2}{*}{ Specificity* } \\
\hline & & Malignant & Benign & & \\
\hline \multicolumn{6}{|l|}{ Cytology } \\
\hline $\begin{array}{l}\text { Suspicious } \\
\text { Benign }\end{array}$ & 0 & 0 & 0 & \multirow{2}{*}{$100 \%$} & \multirow{2}{*}{$100 \%$} \\
\hline $\begin{array}{l}\text { Benign } \\
\text { Unsatisfactory }\end{array}$ & $\begin{array}{r}44 \\
\quad 2\end{array}$ & $\begin{array}{l}0 \\
0\end{array}$ & $\begin{array}{r}44 \\
2\end{array}$ & & \\
\hline \multicolumn{6}{|l|}{ Histology } \\
\hline Suspicious & 2 & 2 & 0 & \multirow{3}{*}{$88.9 \%$} & \multirow{3}{*}{$97 \cdot 8 \%$} \\
\hline Benign & 43 & 1 & 42 & & \\
\hline Unsatisfactory & 4 & 1 & 3 & & \\
\hline
\end{tabular}

*Malignant and suspicious reports are added together in calculating the sensitivity and specificity.

The final diagnosis was malignant in 18 and benign in 46 patients. Eight of the patients with carcinoma had a resection, and one further case had a laparotomy but the lesion was found to be inoperable. The remaining nine patients were considered unfit for surgery. In two of these, carcinoma was confirmed by postmortem histology, but in the other seven cases the malignant diagnosis rests on the clinical course of the disease. All seven were dead within 18 months of diagnosis. One of the patients in the benign group was subsequently found to have a primary carcinoma of the breast, but the others are alive and well on follow-up over a period ranging from two to four years. Six of the patients have had one or more repeated endoscopies with further negative cytology and histology, and one patient has had a laparotomy with negative findings. The patient with negative cytology and false positive histology had a resection. Extensive examination of the operative specimen showed chronic peptic ulceration and no evidence of malignancy. The benign diagnosis of the remaining cases is based on their continuing clinical good health.

Table 2 analyses the results obtained from the two cytology techniques and the histology in the 18 malignant cases. It can be seen that a definitive diagnosis of malignancy was made in all 18 cases by biopsy touch smear cytology. Two patients had false negative or unsatisfactory histology, but in both cases there was sufficient 'cellular' evidence for a firm cytological diagnosis of malignancy to be made from the biopsy touch smears. A definitive cytological diagnosis was also made in the two cases with 'suspicious' histology. Table 3 shows the results of multiple cytology specimens in the 18 malignant cases. In nine cases $(50 \%)$ at least one specimen was

Table 2 Results of brush and biopsy smear cytology and biopsy histology in 18 malignant cases

\begin{tabular}{llll}
\hline Result & \multicolumn{2}{l}{ Cytology } & Histology \\
\cline { 2 - 4 } & Brush & Biopsy touch smear & \\
\hline Malignant & 14 & 18 & 14 \\
Suspicious & 0 & 0 & 2 \\
Benign & 2 & 0 & 1 \\
Unsatisfactory & 1 & 0 & 1 \\
Not done & 1 & 0 & 0 \\
Sensitivity & $82.3 \%$ & $100 \%$ & $88.9 \%$ \\
\hline
\end{tabular}

Table 3 Results of multiple cytology specimens in 18 malignant cases

\begin{tabular}{lrl}
\hline $\begin{array}{l}\text { Cytology specimens } \\
\text { positive }\end{array}$ & $\begin{array}{l}\text { All specimens } \\
\text { negative or unsatisfac- } \\
\text { tory }\end{array}$ \\
\hline Brush and biopsy touch & $9 / 18(50 \%)$ & $9 / 18(50 \%)$ \\
$\quad$ smears & $11 / 18(61 \%)$ & $7 / 18(39 \%)$ \\
Biopsy touch smears & $14 / 17(82 \%)$ & $3 / 17(18 \%)$ \\
Brushes & \\
\hline
\end{tabular}


negative, and even the touch smears, which overall were $100 \%$ accurate, gave a negative result from at least one biopsy in seven cases $(39 \%)$. Although in two of the positive cases in our series only a single biopsy was collected, the need for multiple specimens from each patient is shown by the results in Table 3. A single biopsy is insufficient for a reliable negative result.

Histological assessment (endoscopic biopsies plus operative and postmortem specimens as available) showed 13 of the tumours to be adenocarcinomas, three were of squamous cell type, and two were anaplastic carcinomas. The tumour type was correctly identified by cytology in 12 cases, but in the other six cases the cells were too poorly differentiated to permit typing. There was no problem in any of these six cases in typing the tumour by endoscopic biopsy histology.

\section{Discussion}

In this admittedly small series biopsy touch smear cytology provided a sensitivity and specificity of $100 \%$ in the identification of carcinoma of the lower oesophagus and cardia. For this purpose it was superior to both brush cytology and biopsy histology. Biopsy histology failed to give a positive diagnosis in two of the malignant cases. In two further cases the reports were 'suspicious' of malignancy, but a definitive histological diagnosis was not made. In addition, there was one false positive endoscopic histology result. In this series it was possible to obtain tissue samples with the biopsy forceps from all the patients. The two patients with 'unsatisfactory' touch smear cytology both had 'adequate' biopsy histology and the four patients with 'unsatisfactory' histology had 'adequate' touch smears. The fact that tissue samples were obtainable from all cases would account for the finding that brush cytology contributed nothing to the overall accuracy of the endoscopic examination in any of these 64 patients. From this it appears that brushing should be reserved for those cases in which stenosis is so severe that biopsy forceps cannot be manipulated satisfactorily.

Biopsy touch smear cytology is a little used diagnostic method. Its value in the identification of cancers of the stomach has been reported in three papers from Japan. ${ }^{11-13}$ Apart from these and our own study of the stomach and duodenum, ${ }^{5}$ we are not aware of any other reports of its use in the upper digestive tract. Personal experience suggests that the value of touch smear cytology comes from a combination of the advantages of two diagnostic techniques: tissue biopsy as a means of sampling, and cytological preparations and criteria as the basis of diagnosis. Since the biopsy forceps can obtain a specimen from deeper tissue than the brush, it is able to sample tumours which are primarily submucosal as well as those that are superficial. In addition, when there is extensive surface necrosis of a tumour so that superficial brushings contain only large quantities of degenerate cellular debris, the biopsy forceps can obtain well preserved cells from the deeper layers of the lesion. Moreover, material that is unsatisfactory or inadequate for histological interpretation may still yield a positive result at a 'cellular level', as even a few viable malignant cells in a touch smear are sufficient for diagnosis. Even in adequate histological sections single malignant cells or small clusters of cells may be overlooked or underestimated if there are insufficient cells present to give 'tissue pattern' diagnosis of malignancy, but such cells are readily recognised as malignant when the criteria applied are those of individual cellular morphology.

It must, however, be emphasised that multiple biopsies are necessary for high diagnostic accuracy. A single biopsy, even if technically satisfactory, is insufficient to avoid the possibility of a false negative report. Care at every stage of collection, preparation, and reporting is required to obtain optimum results from endoscopic biopsies. Although in this study it proved possible to obtain a biopsy that produced either adequate touch smears or histological sections from every patient, this was only a small series investigated under 'trial' conditions. It is, however, quicker, easier, and cheaper to prepare six to eight touch smears before fixation of each biopsy for routine sectioning than to undertake the numerous sections (up to 30 per biopsy) advocated by some authorities ${ }^{14}$ as necessary for optimum histological accuracy.

Although highly accurate in the identification of malignancy, touch smear cytology can provide no information about the depth of invasion and is less successful than biopsy histology in typing tumours. The two techniques of touch smear cytology and histology remain complementary and both should be utilised for maximum diagnostic efficiency.

We conclude that touch smear cytology from multiple biopsies is a more highly sensitive and specific technique for the identification of carcinoma of the oesophagus and cardia than either brush cytology or biopsy histology. The latter method, however, is necessary to assess invasion and for tumour typing. Biopsy touch smear cytology is at present a little used diagnostic method in the digestive tract. In the difficult area of the lower oesophagus and cardia, the value of the method has been demonstrated.

This work forms part of a project supported by a 
grant from the Scottish Home and Health Department.

We thank the clinicians who referred their patients and collected the specimens, especially the staff of the Professorial Department of Surgery and of the Gastro-enterology Unit, Glasgow Royal Infirmary. We are very grateful to the many members of the Pathology Department, who reported the histology, and to the technical staff of the Cytology Department for their assistance.

\section{References}

${ }^{1}$ Prolla JC, Reilly RW, Kirsner JB, Cockerham L. Direct vision endoscopic cytology and biopsy in the diagnosis of esophageal and gastric tumors. Acta Cytol 1977;21: 399-402.

${ }^{2}$ Kasugai T, Kobayashi S, Kuno N. Endoscopic cytology of the esophagus, stomach and pancreas. Acta Cytol $1978 ; 22: 327-30$.

${ }^{3}$ Hishon S, Lovell D, Gummer JWP, Smithies A, Shawdon H, Blendis LM. Cytology in the diagnosis of oesophageal cancer. Lancet 1976;1:296-7.

${ }^{4}$ Keighley MRB, Thompson $\mathrm{H}$, Moore J, Hoare AM, Allen RN, Dykes PW. Comparison of brush cytology before and after biopsy for diagnosis of gastric carcinoma. Br J Surg 1979;66:246-7.

5 Young JA, Hughes HE. Report of a three year trial of endoscopic cytology of the stomach and duodenum. Gut (in press).
6 Winawer SJ, Sherlock P, Hajdu SI. The role of upper gastrointestinal endoscopy in patients with cancer. Cancer 1976;37:440-8.

' Witzel L, Halter F, Gretillat PA, Scheurer U, Keller M. Evaluation of specific value of endoscopic biopsies and brush cytology for malignancies of the oesophagus and stomach. Gut 1976;17:375-7.

${ }^{8}$ Bruni HC, Nelson RS. Carcinoma of the oesophagus and cardia; diagnostic evaluation in 113 cases. $J$ Thorac Cardiovasc Surg 1975;70:367-70.

${ }^{9}$ Hughes HE, Lee FD, MacKenzie JF. Endoscopy, cytology and biopsy in the upper gastrointestinal tract. Clin Gastroenterol 1978;7:375-96.

${ }^{10}$ Cochrane AL, Holland WW. Validation of screening procedures. Br Med Bull $1971 ; 27: 3-8$.

${ }^{11}$ Yoshii Y, Takahashi J, Yamaoka Y, Kasugai T. Significance of imprint smears in cytologic diagnosis of malignant tumours of the stomach. Acta Cytol 1970;14: 249-53

12 Yamakawa I, Parish J, Berci G, et al. The correlation of target biopsy and contact smear cytology under direct visual control in malignant gastric lesions. Gastrointest Endosc 1971;17:164-8.

${ }^{13}$ Tamura K, Masuzawa M, Akiyama T, Fukui O. Touch smear cytology for endoscopic diagnosis of gastric carcinoma. Am J Gastroenterol 1977;67:463-7.

14 Ackerman LV, Del Regato JA. Cancer: Diagnosis, Treatment and Prognosis. 4th ed. St Louis: Mosby, 1970 .

Requests for reprints to: Jennifer A Young, Department of Cytology, The Royal Infirmary, Glasgow, UK. 